Roongroj Bhidayasiri,

MD, FRCP, FRCPI

Neil Brenden, DSW,

$\mathrm{MPH}$

Pramon

Viwattanakulvanid,

PharmD

Onanong Jitkritsadakul, MD

Ray Tabucanon, MD

Priya Jagota, MD

Henning Hojer, MD, $\mathrm{PhD}$

Correspondence to Dr. Bhidayasiri: rbh1@ucla.edu

Supplemental data at Neurology.org

\section{IDENTIFYING GAPS IN KNOWLEDGE ABOUT PARKINSON DISEASE AMONG MEDICAL PROFESSIONALS IN THAILAND}

Although Dr. James Parkinson wrote his classic essay "The Shaking Palsy" almost 200 years ago to inform the scientific and medical communities about the disease that now bears his name, the fundamental dynamics of Parkinson disease (PD) are still not fully understood. ${ }^{1}$ Perhaps because the criteria for diagnosing PD all relate to movements, many people, including physicians, have the misconception that $\mathrm{PD}$ primarily is a movement disorder when, in fact, it has a great impact on many other physical and psychological functions as well. In light of the absence of a definitive understanding of the basic etiology of PD and the comprehensive scope of its impact, the medical responses to this neurodegenerative disease often are influenced by misconceptions based on myths and false assumptions.

Many articles in the professional literature use the terms "misconceptions" and "myths" as synonyms meaning an incorrect understanding. However, there is an important difference in meaning and a precise use of these terms is important in considering the topic of PD knowledge. A misconception is a failure to understand the reality of a situation at a given point in time. ${ }^{2}$ As a result, one's understanding of a situation is incomplete or even false. Myths, on the other hand, are traditional narratives that serve to explain natural and social phenomena. ${ }^{2}$ Indeed, a myth may be functional for individuals or societies and might incorporate empirical truths that are rooted in tradition. In addition, we recognize "false assumptions," which are incorrect judgments that erroneously accept, without evidence, that what is true about one situation or problem is also true about another. ${ }^{2}$

This article is focused on misconceptions related to symptoms, diagnosis, and treatment of PD in the medical community in Thailand. The intention of this contribution is to highlight both similarities and differences in the misconceptions about PD among medical professional groups, to model a methodology for determining the most appropriate content for continuing medical education (CME) curricula, and to increase an appreciation of those factors that contribute to gaps in knowledge when selecting methodologies for CME. This article reports on an initiative of the Center of Excellence for Parkinson's Disease and Related Disorders at Chulalongkorn Hospital to increase the diagnostic and treatment skills of the Thai medical community.

Methods. A questionnaire on knowledge of PD was developed and tested for content validity with the Index of Item-Objective Congruence (appendix e-1 on the Neurology ${ }^{\circledR}$ Web site at Neurology.org). As a result, several questions were deleted for lack of clarity. The final version of the questionnaire contains 26 questions that are divided into 3 sections: diagnosis, pharmacologic options, and progression (appendix e-2). A total of 114 medical professionals, including 28 board-certificated neurologists, 24 neurology residents, 42 internists, 6 general practitioners, and 14 registered nurses, completed the questionnaire. A tabulation of the accuracy of their "true" or "false" responses to statements in the questionnaire is shown in figure 1 . The data were analyzed with an analysis of variance (ANOVA) to compare means of the scores and with descriptive statistical analyses to determine the percentage of incorrect responses to each question among the 5 groups of medical professionals. A $p$ value less than 0.001 was considered statistically significant. Statistical analyses were performed using SPSS version 14.0 software (SPSS Inc., Chicago, IL). The study was approved by the Human Ethical Committee of the Faculty of Medicine of Chulalongkorn University.

Results. As shown in figure 1, there was a statistically significant difference in the average total PD knowledge scores among the 5 groups as determined by 1-way 
Figure 1 Average total scores of PD knowledge

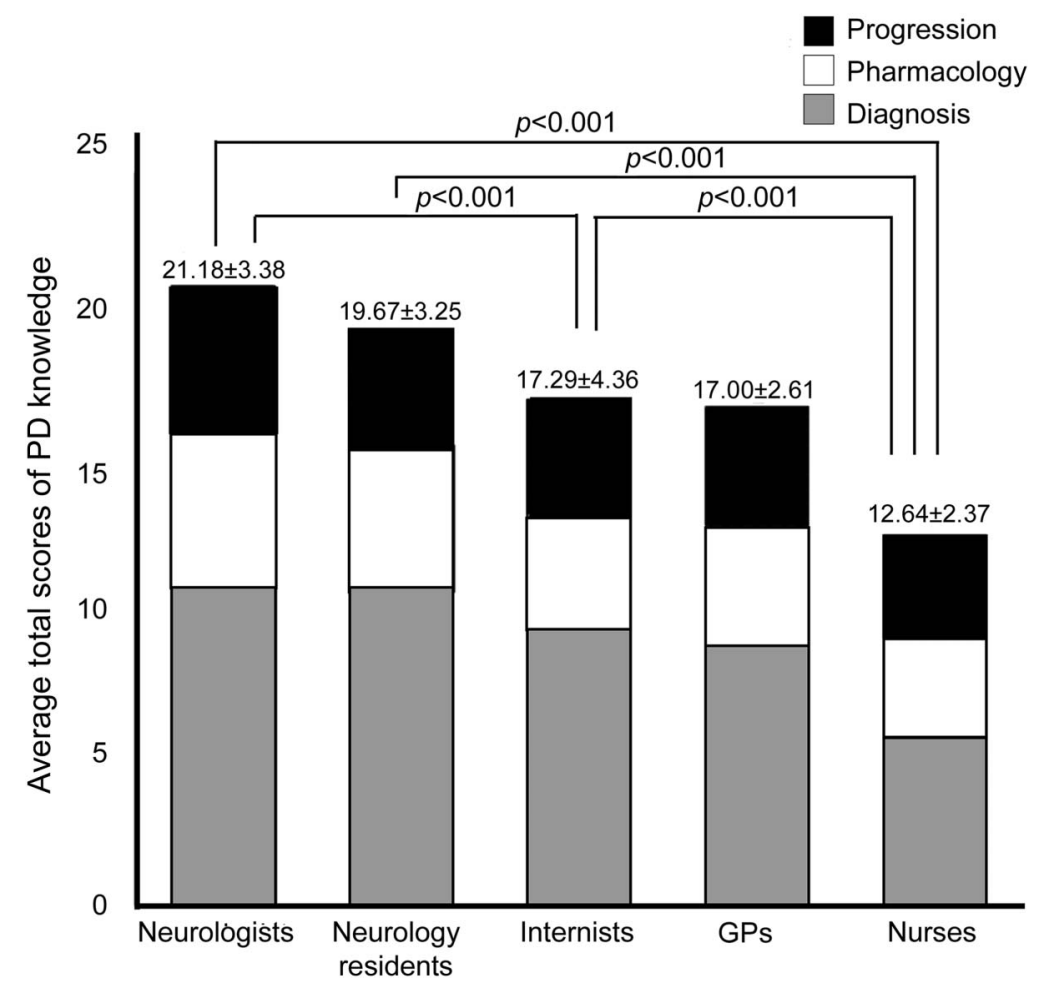

Corrected scores on Parkinson disease (PD) knowledge questionnaire among different groups of medical professionals (total score $=26)(p<0.001$ indicates statistical significance between groups). GP = general practitioner.

$\operatorname{ANOVA}\left(F_{4,109}=14.712\right.$ and $\left.p=0.00\right)$. All of the medical professionals in the sample had many incorrect responses about $\mathrm{PD}$ in common in each section, as illustrated in figure 2 and appendix e-3. In the diagnosis section of the questionnaire, many in all 5 groups had misconceptions about the prodromal nonmotor symptoms, diagnostic criteria, and risk factors for PD. In the pharmacologic section, many in all the groups had an inaccurate assessment of the benefits of PD medications and treatment guidelines. In the progression section, all the groups shared misconceptions about PD disabilities, deep brain stimulation, PD progression, and the relationship between subtypes of PD and PD progression.

Discussion. A review of the incorrect responses on the questionnaire revealed substantial PD knowledge gaps among medical professionals, which informed recommendations for CME for each group. Although the board-certificated neurologists had the highest average scores in the sample, their CME curriculum should update them with information about PD on a regular basis. Neurology residents require additional training in the same areas as board-certificated neurologists plus intensive instruction on pharmacologic options. Internists require basic training in $\mathrm{PD}$ diagnosis and indications for referring patients to neurologists. For general practitioners, who provide most of the medical care for patients with PD in Thailand, ${ }^{3}$ the knowledge gaps include basic PD diagnosis and treatment plus indications for referring patients to a board-certificated neurologist. Registered nurses play a critical role in multidisciplinary teams and their relatively low average scores indicate a need to enhance their PD knowledge and skills in the basics of diagnosis, treatment, and support.

In Thailand, PD information is shared through academic associations such as Thai Parkinson's Disease and Movement Disorders Society and The Neurological Society of Thailand, which act as core bodies to develop CME. ${ }^{4}$ Appropriate methodologies are critical to the success of CME initiatives in addition to the contents of the curricula as noted above. Misconceptions often are based on false assumptions or myths, or various combinations of these important determinants of what is believed to be true. In developing effective methodologies for CME, it is important to determine what is supporting or promoting the errors and gaps in PD knowledge. Those misconceptions that are based on false assumptions may be effectively addressed through traditional didactic training methods such as presentations at conferences and articles in professional journals. But misconceptions that are influenced, and even determined, by myths require more process-oriented methodologies such as seminars and small group discussions that promote reflection by the medical professionals on decisions made in the course of treating patients and their rationale. ${ }^{5}$

In order to correct misconceptions about PD, we propose that education and training on PD should be extensively covered in medical schools and continue as CME shaped by formative research on both content and training methodologies throughout the careers of medical professionals. Further studies should be considered on how to refine the operational definitions of myth and false assumption, and longitudinal assessment of the impact of knowledge should be implemented to evaluate the efficacy of training methodologies that are selected on the basis of factors that influence misconceptions. Some of these initiatives have already taken place, such as the introduction of a basic movement disorders course in Chiang Mai, Thailand, which was well-attended by medical professionals from Thailand, Myanmar, and Laos (http://www.movementdisorders.org/regional_ sections/reports/chiang-mai-thailand.php). Moreover, comparison of data with other countries in the region 
A. PD diagnosis

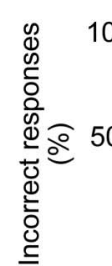

The presence of rest tremor is mandatory for the diagnosis of PD
Mood disorders are one of the symptoms of PD that often precedes tremors and/or bradykinesia

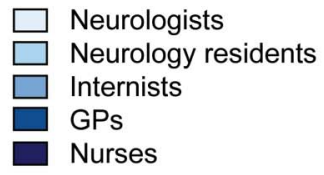

Both smoking and high caffeine consumption increase the risk of PD

\section{B. PD pharmacologic options}

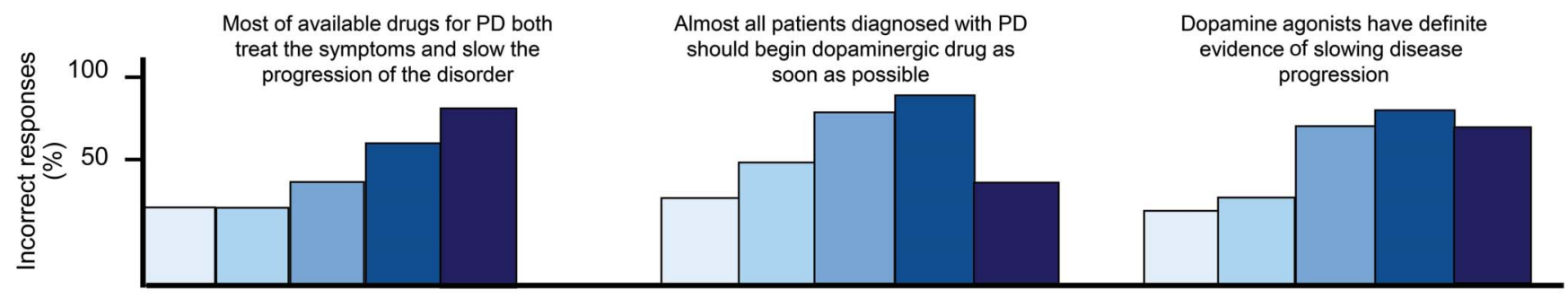

\section{PD progression}

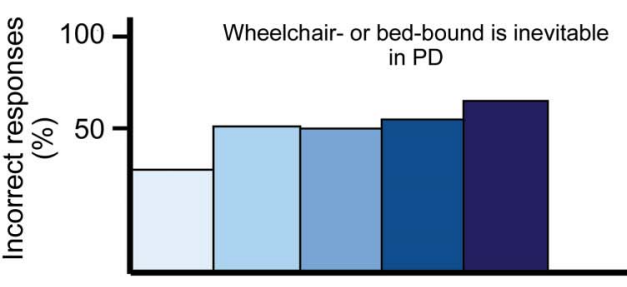

Patients with tremor-predominant symptoms progress more rapidly in the degenerative process than those with postural instability and gait problems
Deep brain stimulation surgery can stop PD progression

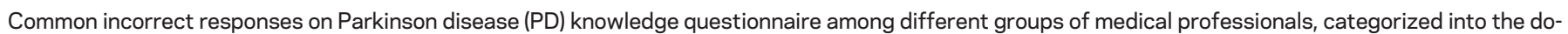
mains of diagnosis (A), pharmacologic options $(B)$, and disease progression (C). GP = general practitioner.

would strengthen the programs of international medical educations currently developed by various medical associations.

\section{AUTHOR CONTRIBUTIONS}

Dr. Bhidayasiri: conception of the research project, organization of the research project, execution of the research project, statistical analysis review and critique, manuscript review and critique. N. Brenden: conception of the research project, execution of the research project, statistical analysis review and critique, writing of the first draft, manuscript review and critique. Dr. Viwattanakulvanid: statistical analysis design, statistical analysis execution, statistical analysis review and critique. Dr. Jitkritsadakul: statistical analysis design, statistical analysis execution. Dr. Tabucanon: organization of the research project, execution of the research project. Dr. Jagota: organization of the research project, manuscript review and critique. Henning Hojer: writing of the first draft, manuscript review and critique.

\section{STUDY FUNDING}

Supported by The Rachadaphiseksomphot Endowment Fund of the "Strengthen CU's Researcher's Project." Research unit (RU) grant number GRU 52-026-30-005 of Chulalongkorn University, Bangkok, Thailand.

\section{DISCLOSURE}

The authors report no disclosures relevant to the manuscript. Go to Neurology.org for full disclosures.

\section{REFERENCES}

1. Stern MB, Lang A, Poewe W. Toward a redefinition of Parkinson's disease. Mov Disord 2012;27:54-60.

2. Shorter Oxford English Dictionary, 5th ed. New York: Oxford University Press; 2002.

3. Bhidayasiri R, Wannachai N, Limpabandhu S, et al. A national registry to determine the distribution and prevalence of Parkinson's disease in Thailand: implications of urbanization and pesticides as risk factors for Parkinson's disease. Neuroepidemiology 2011;37:222-230.

4. Boongird P, Soranastaporn S, Menken M, Vejjajiva A. The practice of neurology in Thailand: a different type of medical specialist. Arch Neurol 1993;50:311-312.

5. Brigley S, Young Y, Littlejohns P, McEwen J. Continuing education for medical professionals: a reflective model. Postgrad Med J 1997;73:23-26. 


\section{Neurology}

\section{Identifying gaps in knowledge about Parkinson disease among medical professionals in Thailand}

Roongroj Bhidayasiri, Neil Brenden, Pramon Viwattanakulvanid, et al. Neurology 2014;82;2238-2240

DOI 10.1212/WNL.0000000000000515

This information is current as of June 16, 2014

$\begin{array}{ll}\begin{array}{l}\text { Updated Information \& } \\ \text { Services }\end{array} & \begin{array}{l}\text { including high resolution figures, can be found at: } \\ \text { http://n.neurology.org/content/82/24/2238.full }\end{array} \\ \text { Supplementary Material } & \text { Supplementary material can be found at: } \\ \text { http://n.neurology.org/content/suppl/2014/06/15/82.24.2238.DC1 } & \text { This article cites } 4 \text { articles, } 1 \text { of which you can access for free at: } \\ \text { http://n.neurology.org/content/82/24/2238.full\#ref-list-1 } & \\ \text { References } & \text { This article, along with others on similar topics, appears in the } \\ \text { following collection(s): } & \text { CME } \\ \text { http://n.neurology.org/cgi/collection/cme } & \text { Parkinson's disease/Parkinsonism } \\ & \text { http://n.neurology.org/cgi/collection/parkinsons_disease_parkinsonism } \\ & \text { Information about reproducing this article in parts (figures,tables) or in } \\ \text { its entirety can be found online at: } & \text { http://www.neurology.org/about/about_the_journal\#permissions } \\ \text { Permissions \& Licensing } & \text { Information about ordering reprints can be found online: } \\ \text { http://n.neurology.org/subscribers/advertise }\end{array}$

Neurology ${ }^{\circledR}$ is the official journal of the American Academy of Neurology. Published continuously since 1951, it is now a weekly with 48 issues per year. Copyright @ 2014 American Academy of Neurology. All rights reserved. Print ISSN: 0028-3878. Online ISSN: 1526-632X.

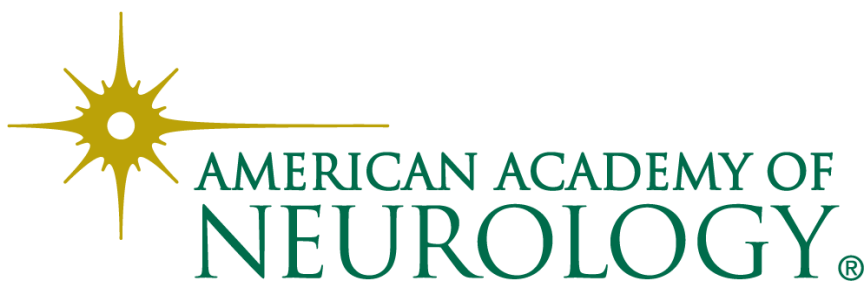

